\title{
Domestic Violence among Pregnant Mothers in Northwest Ethiopia: Prevalence and Associated Factors
}

\author{
Berhanu Boru Bifftu, ${ }^{1}$ Berihun Assefa Dachew, ${ }^{2}$ \\ Bewket Tadesse Tiruneh, ${ }^{1}$ and Abarham Zeleke Zewoldie ${ }^{3}$ \\ ${ }^{1}$ Department of Nursing, University of Gondar College of Medicine and Health Sciences, Gondar, Ethiopia \\ ${ }^{2}$ Department of Epidemiology and Biostatistics, University of Gondar College of Medicine and Health Sciences, \\ Institute of Public Health, Gondar, Ethiopia \\ ${ }^{3}$ Federal Ministry of Health, Medical Service Directorate, Addis Ababa, Ethiopia
}

Correspondence should be addressed to Berhanu Boru Bifftu; berhanuboru@gmail.com

Received 4 April 2017; Revised 28 September 2017; Accepted 7 November 2017; Published 5 December 2017

Academic Editor: Paul Van Royen

Copyright (C) 2017 Berhanu Boru Bifftu et al. This is an open access article distributed under the Creative Commons Attribution License, which permits unrestricted use, distribution, and reproduction in any medium, provided the original work is properly cited.

\begin{abstract}
Background. Domestic violence against women is a serious public health concern and human rights violation among pregnant mothers because of its negative effect on the life of both the mother and the fetus. Thus, the aim of this study was to assess the prevalence of domestic violence and associated factors among pregnant women. Methods. An institution based quantitative crosssectional study was conducted among 418 women using a systematic random sampling technique. Binary logistic regression analysis and adjusted odds ratio with $95 \%$ confidence interval were used to identify the associated factors. Results. Overall, the prevalence of domestic violence was found to be $25.4 \%$. Of this, the prevalence of psychological, physical, and sexual violence was $24.5 \%$, $8.1 \%$, and $2.4 \%$, respectively. Low educational status $(\mathrm{AOR}=4.59, \mathrm{CI}: 1.496,14.070)$, rural residency $(\mathrm{AOR}=5.53, \mathrm{CI}: 2.311,13.249)$, unplanned pregnancy $(\mathrm{AOR}=4.34, \mathrm{CI}: 2.345,8.020)$, and late initiation of antenatal care $(\mathrm{AOR}=5.41, \mathrm{CI}: 1.493,19.696)$ were factors associated with domestic violence at $p$ value $<0.05$. Conclusion. Overall, more than quarter of the study participants had experienced domestic violence. Lower educational status, rural residency, unplanned pregnancy, and late initiation of antenatal care were factors associated with domestic violence. Thus, the authors suggest strengthening provision of women's reproductive health information.
\end{abstract}

\section{Background}

Despite the Universal Declaration of the Human Rights, as all people begin to be recognized regardless of age, sex, race, color, language, religion, or any other factors, women have continued to suffer from domestic violence and discrimination in their homes and/or society [1]. According to the World Health Organization (WHO), domestic violence was defined as "the range of sexually, psychologically, and physically coercive acts used against adult and adolescent women with current or former male intimate partners" [2]. Domestic violence during pregnancy is the physical, sexual, or psychological violence, inflicted on a pregnant woman by a current or former male intimate partner [3].

Globally, the magnitude of domestic violence against women is a serious public health concern [4]. For example, according to a WHO multicountry study, the lifetime prevalence of physical, sexual, or both physical and sexual violence ranges from $15 \%$ to $71 \%$ [5]. During pregnancy, the prevalence of domestic violence ranges from 1 to $28 \%$ [2] and from Africa it ranges from 2\% to 57\% [6]. In Ethiopia, domestic violence has been documented as a culture specific phenomenon and is influenced by religion and the sociocultural context [4]. For example, the available evidence revealed the widespread agreement of wife beating and high prevalence of domestic violence [7]. A recently released report of Ethiopian Demographic and Health Survey (2016 EDHS) revealed the existence of still high prevalence of domestic violence with the form of physical, emotional, or sexual violence, and from this report, it is observed that the prevalence of domestic violence was increased against older women (40-49), formerly married women, women living in rural 
areas, and women with lower educational level [8]. There are also other community based studies that revealed the existence of domestic violence with the prevalence ranging from 50 to $76.5 \%$ during lifetime and from 30 to $72.5 \%$ for the past 12 months [8-10], and for pregnant mothers, the reported prevalence of domestic violence ranged from $32.2 \%$ (of this, the prevalence of physical, psychological, and sexual violence was $14.8 \%, 24.9 \%$, and $11.3 \%$, resp. [11]) to $44.5 \%$ (of this, $29.2 \%, 16.3 \%$, and $30 \%$ of physical, psychological, and sexual violence were and $14.8 \%, 24.9 \%$, and $11.3 \%$, resp.) $[12,13]$.

Domestic violence affects all the spheres of women's lives such as self-esteem, productivity, autonomy, capacity to care for themselves and their children, ability to participate in social activities, and even death $[4,5]$. For pregnant mothers, domestic violence has special concern due to the potential negative impacts for both the mother and the unborn infants, such as placental damage, rupture of the uterus, fetal trauma $[2,6,12]$, spontaneous abortion, bleeding, preterm labor, preterm delivery, low birth weight, and death [13-15]. Studies from developed and some developing countries revealed the presence of high magnitude of domestic violence and its negative consequences [2,6]. In Ethiopia, even though studies were carry out on women, little attention was given for pregnant mothers. Thus, the aim of this study was to assess the prevalence of domestic violence and associated factors among pregnant women.

\section{Methods}

2.1. Study Design. A clinical based cross-sectional quantitative study design was conducted.

2.2. Study Area. The study was carried out in Gondar town, Northwest Ethiopia. Gondar town is located at 748 kilometers from the capital city of Ethiopia, Addis Ababa.

2.3. Sampling Procedure and Sample Size. Participants of the study were all pregnant mothers seen and followed up at the antenatal care clinics of public health facilities in Gondar town. The sample size of the study was determined based on the Leslie-Kish formula, $n=z^{2} p(1-p) / d^{2}$, where $z$ is the normal standard deviation set at 1.96, with a confidence level specified at $95 \%$ and a tolerable margin of error $(d)$ at $5 \%$, and based on prevalence $(p)$ of $50 \%$ and considering $10 \%$ nonresponse rate, the minimum sample size $(n)$ was 422 . For the sampling procedure, first, all public health facilities in Gondar town were considered, and then based on the number of pregnant women that visited each health facility during the previous year, proportional allocation of the total sample size was carried out to get the required sample size from each health facility. Finally, the determined samples were selected by a systematic random sampling technique.

2.4. Instruments. For the assessment of domestic violence, the WHO (2005) multicountry study questionnaire was used. This questionnaire has four items for psychological violence, six items for physical violence, and three additional items for sexual violence [2]. In this study, the prevalence of domestic violence was defined as any violence whether physical, psychological, and sexual or any combination of the three, regardless of the legal status of the relationship. Physical violence was defined as one or more intentional acts of physical aggression such as pushing, slapping, throwing, hair pulling, punching, hitting, kicking, or burning, perpetrated with the potential to cause harm, injury, or death. Psychological/emotional violence was defined as one or more acts or threats of acts, such as shouting, controlling, intimidating, humiliating, and threatening the victim. Sexual violence is defined as the use of force, coercion, or psychological intimidation to force the woman to engage in a sex act against her will, whether or not it is completed. Social support was measured with a 12-item multidimensional Likert type agreement scale. The total sums of score range from 7 to 84 . High level of perceived social support was defined as a score between 69 and 84, moderate level of perceived social support was defined as a score between 49 and 68, and low level of perceived social support was defined as a score between 12 and $48[16]$.

2.5. Data Collection and Analysis. Quantitative crosssectional data were collected by face-to-face intervieweradministered techniques using paper and pen in a private room. Data were coded and entered into EPI Info version 3.5.3 statistical software and then exported to SPSS for Windows version 20 program for analysis. Descriptive statistics (like frequencies, tables, percentages, means, and standard deviation) were used for the description part. Bivariate and multivariable logistic regression with an odds ratio of $95 \%$ confidence interval were used to identify the associated factors. A significance level of 0.05 was taken as a cut-off value for all statistical significance tests.

2.6. Ethical Consideration. A formal letter of permission was obtained from the Institutional Review Board (IRB) of the University of Gondar and submitted to each health institution. After clear and detailed explanation of the purpose, risks, and benefits of the study to the study subjects, written informed consent was sought for each participant who agreed to participate in the study. Only anonymous data was collected in private rooms.

\section{Results}

Four hundred twenty-two participants were targeted for this study. Of these, 418 participants were enrolled with a response rate of $99.1 \%$.

3.1. Sociodemographic Characteristics of the Respondents. The mean age of the respondents was $26.99 \pm 9.86$ (SD) years and $171(40.9 \%)$ of the mothers were in the age range of $25-29$ years. Three hundred seventy-four (89.5\%) of the respondents belonged to Amhara by ethnicity and $317(75.8 \%)$ were Orthodox Christian in religion. Regarding the marital status, majority $(375,89.2 \%)$ of them were married. One hundred forty-two $(34 \%)$ of the mothers had secondary education. 
TABLE 1: Sociodemographic characteristics of participants in Gondar town, 2015 ( $n=418)$.

\begin{tabular}{|c|c|c|}
\hline Characteristics & Frequency & Percent \\
\hline \multicolumn{3}{|l|}{ Age } \\
\hline $17-19$ & 21 & 5 \\
\hline $20-24$ & 115 & 27.5 \\
\hline $25-29$ & 171 & 40.9 \\
\hline $30+$ & 111 & 26.6 \\
\hline \multicolumn{3}{|l|}{ Current marital status } \\
\hline Single & 39 & 9.3 \\
\hline Married & 373 & 89.2 \\
\hline Divorced/separated & 5 & 1.2 \\
\hline Widowed & 1 & 0.2 \\
\hline \multicolumn{3}{|l|}{ Religion } \\
\hline Orthodox Christian & 317 & 75.8 \\
\hline Muslim & 71 & 17 \\
\hline Protestant & 30 & 7.2 \\
\hline \multicolumn{3}{|l|}{ Ethnicity } \\
\hline Amhara & 374 & 89.5 \\
\hline Tigre & 28 & 6.7 \\
\hline Oromo & 16 & 3.8 \\
\hline \multicolumn{3}{|l|}{ Educational status } \\
\hline Cannot read and write & 102 & 24.4 \\
\hline Primary education & 76 & 18.2 \\
\hline Secondary education & 142 & 34 \\
\hline College and above & 98 & 23.4 \\
\hline \multicolumn{3}{|l|}{ Occupational } \\
\hline Governmental & 65 & 15.6 \\
\hline Merchant & 113 & 27 \\
\hline Farmer & 30 & 7.2 \\
\hline Housewife & 159 & 38 \\
\hline Daily laborer & 25 & 6 \\
\hline Unemployed & 26 & 6.2 \\
\hline \multicolumn{3}{|l|}{ Residence } \\
\hline Rural & 54 & 12.9 \\
\hline Urban & 364 & 87.1 \\
\hline \multicolumn{3}{|l|}{ Social support } \\
\hline High level of social support & 66 & 15.8 \\
\hline Moderate level of social support & 329 & 78.7 \\
\hline Low level of social support & 23 & 5.5 \\
\hline
\end{tabular}

Out of 418 participants, 159 (38\%) were housewives and 364 $(87.1 \%)$ were living in urban areas (Table 1$)$.

3.2. Obstetric Related History of the Respondents. Three hundred and five $(73 \%)$ of the mothers had a history of planned pregnancy and 394 (94.3\%) wanted to be pregnant. Fortyfour $(10.5 \%)$ of the mothers had a history of abortion, 237 (56.7\%) of the mothers had a history of multigravidity, and $224(53.6 \%)$ of the mothers had a history of multiparity (Table 2).
TABLE 2: Obstetrics related characteristics of participants in Gondar town, $2015(n=418)$.

\begin{tabular}{lcc}
\hline Variables & Frequency & Percent \\
\hline Planned pregnancy & 305 & \\
Yes & 113 & 73 \\
No & & 27 \\
Wanted pregnancy & 394 & \\
Yes & 24 & 94.3 \\
No & & 5.7 \\
First ANC initiation & 142 & \\
First trimester & 247 & 34 \\
Second trimester & 29 & 59.1 \\
Third trimester & & 6.9 \\
History of abortion & 44 & \\
Yes & 374 & 10.5 \\
No & & 89.5 \\
Parity & 194 & 46.4 \\
Nulliparous & 224 & 53.6 \\
Multiparous & & \\
Gravidity & 181 & 43.3 \\
Primigravida & 237 & 56.7 \\
Multigravida & &
\end{tabular}

3.3. Prevalence of Domestic Violence. Overall, the prevalence of domestic violence was found to be $25.4 \%$. Of this, the prevalence of psychological, physical, and sexual violence was $24.5 \%, 8.1 \%$, and $2.4 \%$, respectively. Regarding the frequencies of violence toward each item, $85(20.3 \%)$ of the participants were insulted/made feel bad about themselves (Table 3).

3.4. Factors Associated with Domestic Violence. From the bivariate analysis, variables that have $p$ value $<0.2$ such as marital status, educational status, employment, residence, social support, unplanned pregnancy, late ANC initiation, history of abortion, parity, and gravidity were entered into multivariable analysis. From the multivariable analysis, primary educational status $(\mathrm{AOR}=4.59, \mathrm{CI}: 1.496,14.070)$, rural residency $(\mathrm{AOR}=5.53, \mathrm{CI}: 2.311,13.249)$, unplanned pregnancy $(\mathrm{AOR}=4.34, \mathrm{CI}: 2.345,8.020)$, and first ANC initiation $(\mathrm{AOR}=5.41, \mathrm{CI}: 1.493,19.696)$ were factors significantly associated with domestic violence at $p$ value $<0.05$ (Table 4).

\section{Discussion}

In this cross-sectional study, the overall prevalence of domestic violence was found to be $25.4 \%$, associated with lower educational status, rural residency, unplanned pregnancy, and late ANC initiation. Out of the overall prevalence of $25.4 \%$, $24.5 \%$ was emotional violence, $8.1 \%$ was physical violence, and $2.4 \%$ was sexual violence. This result (25.4\%) is similar to the studies carried out in Uganda (27.7\%) [17] and Nigeria (28.3\%) [18], but lower compared to the studies carried out in Zimbabwe (61.3\%) [19], Rwanda (35.1\%) [20], South Africa (31\%) [21] Nigeria (34.3\%) [22], and Kenya (37\%) [23] and the 
TABLE 3: Frequencies of domestic violence toward each item of WHO tools in Gondar town, $2015(n=418)$.

\begin{tabular}{lcc}
\hline Violence items & Frequency & 103 \\
\hline Psychological violence & 85 & 24.5 \\
Insulted/made feel bad about self & 26 & 20.3 \\
Belittled or humiliated in front of other people & 76 & 6.2 \\
Scared or intimidated on purpose & 15 & 18.2 \\
Threatened when asking friends/family & 34 \\
Physical violence & 31 & 3.6 \\
Slapped you or thrown something at you that could hurt you? & 11 & 8.1 \\
Pushed you or shoved or pulled your hair? & 15 & 7.7 \\
Hit you with his fist or with something else that could hurt you? & 2 & 2.6 \\
Kicked or dragged you or beat you & 1 \\
Choked or burnt you on purpose? & 2 \\
Threatened to use or actually used a gun, knife, or any other weapon against you? & 3.6 \\
Sexual violence & 0.5 \\
Physically forced you to have sexual intercourse & 0.2 \\
Having unwanted sexual intercourse because of fear from the partner & 5 \\
Forced you to do something sexual that is degrading or humiliating & 0.5 \\
Overall violence & 7 \\
\hline
\end{tabular}

studies conducted in Ethiopia (32.2\% [11] and 44.5\% [12]). In contrast, the prevalence of domestic violence in this study is higher than in the studies carried out in America (16.8\%) [24] and Nigeria (11.6\% [25] and 7.4\% [26]). The possible explanation for the variation may be due to the difference in educational level, accessibility of information on gender based issues, reproductive health information, the studies design, geographical areas, and the cultures of the study subjects.

Regarding the associated factors, those women who had primary educational status $[(\mathrm{AOR}=4.59, \mathrm{CI}: 1.496,14.070)]$ experienced domestic violence more than four times higher compared to those with educational status of college and above. This result is consistent with the previous studies [13, 27]. This might be due to the fact that uneducated pregnant women may not have the ability to have a discussion with their partners to resolve any disagreement. Evidence revealed that low levels of education and lack of decision-making power increase women's likelihood of experiencing domestic violence during pregnancy [9].

Those women who participated in the study from rural residences $[(\mathrm{AOR}=5.53, \mathrm{CI}: 2.311,13.249)]$ experienced domestic violence more than five times higher compared to urban residences. This may be due to the fact that those women who participated in the study from rural residences may not have accessed different information that deals with gender equality, women's right, and violence reduction strategies.

Those women with unplanned pregnancy $[(\mathrm{AOR}=4.34$, CI: $2.345,8.020)]$ experienced domestic violence more than four times higher compared to women with planned pregnancy. This may be due to the fear of taking the responsibility to care for both the mother and the newly coming child or this unplanned pregnancy may be the result of sexual violence.
Studies revealed that sexual violence is one of the causes of unplanned pregnancy $[13,27,28]$.

Those women who start their ANC during the third trimesters $[(\mathrm{AOR}=5.41, \mathrm{CI}: 1.493,19.696)]$ experienced domestic violence more than five times higher compared to those that started their ANC during the first trimester. This result is consistent with another study [29]. This may be due to the lower socioeconomic problem and lack of information on the advantage of on-time ANC initiation. This can be supported by other studies [26,30].

4.1. Limitation of the Study. This study has some important limitations that should be considered when interpreting the results. First the cross-sectional nature of the study design does not confirm definitive cause and effect relationship between dependent and independent variables. Second, there might be recall and social desirability bias due to the sensitive nature of domestic violence and cultural barrier to disclose partners issue to third parties.

4.2. Conclusion and Recommendations. Overall, more than a quarter of the study participants experienced domestic violence. Lower educational status, rural residency, unplanned pregnancy, and late ANC initiation were factors statistically significant with domestic violence. Thus, the authors suggest strengthening the provision of women's reproductive health information since it has advantages for planned pregnancy and time of initiation of ANC.

\section{Disclosure}

The funder had no role in study design, data collection, analysis, and decision to publish. The corresponding author 
TABLE 4: Factors associated with domestic violence (bivariate and multivariable) analysis in Gondar town, $2015(n=418)$.

\begin{tabular}{|c|c|c|c|c|c|}
\hline \multirow{2}{*}{ Explanatory variables } & \multicolumn{2}{|c|}{ Domestic violence } & \multirow{2}{*}{ COR $(95 \% \mathrm{CI})$} & \multirow{2}{*}{$\operatorname{AOR}(95 \% \mathrm{CI})$} & \multirow{2}{*}{$p$ value } \\
\hline & Yes, $N(\%)$ & No, $N(\%)$ & & & \\
\hline $\begin{array}{l}\text { Marital status } \\
\text { Married } \\
\text { Unmarried }\end{array}$ & $\begin{array}{l}84(20.1) \\
22(5.3)\end{array}$ & $\begin{array}{c}289(69.1) \\
23(5.5)\end{array}$ & $\begin{array}{c}1 \\
3.33(1.747,6.197)\end{array}$ & & \\
\hline $\begin{array}{l}\text { Educational status } \\
\text { Cannot read and write } \\
\text { Primary } \\
\text { Secondary } \\
\text { College and above }\end{array}$ & $\begin{array}{c}41(9.8) \\
31(7.4) \\
28(6.7) \\
6(1.4)\end{array}$ & $\begin{array}{c}61(14.6) \\
45(14.6) \\
114(10.8) \\
92(22)\end{array}$ & $\begin{array}{c}10.34(4.124,25.752) \\
10.56(4.109,27.151) \\
3.77(31.496,9.484) \\
1\end{array}$ & $\begin{array}{c}1.40(0.454,4.329) \\
\mathbf{4 . 5 9}(\mathbf{1 . 4 9 6 , 1 4 . 0 7 0 )} \\
2.10(0.706,6.210) \\
1\end{array}$ & $\begin{array}{c}0.557 \\
0.008 \\
0.183 \\
1\end{array}$ \\
\hline $\begin{array}{l}\text { Employment } \\
\text { Government } \\
\text { Merchant } \\
\text { Farmer } \\
\text { Housewife } \\
\text { Daily laborers } \\
\text { Unemployed }\end{array}$ & $\begin{array}{c}7(1.7) \\
19(4.5) \\
24(5.7) \\
31(7.4) \\
15(3.6) \\
10(2.4)\end{array}$ & $\begin{aligned} 58 & (13.9) \\
94 & (22.5) \\
6 & (1.4) \\
128 & (30.6) \\
10 & (2.4) \\
16 & (3.9)\end{aligned}$ & $\begin{array}{c}1 \\
1.23(0.417,3.615) \\
2.28(0.814,6.380) \\
33.14(10.086,13.908) \\
2.01(0.835,4.823) \\
3.68(1.222,7.801)\end{array}$ & & \\
\hline $\begin{array}{l}\text { Residency } \\
\text { Rural } \\
\text { Urban }\end{array}$ & $\begin{array}{c}31(7.4) \\
75(17.9)\end{array}$ & $\begin{array}{c}23(5.5) \\
289(69.1)\end{array}$ & $\begin{array}{c}5.19(2.861,9.427) \\
1\end{array}$ & $\begin{array}{c}5.53(2.311,13.249) \\
1\end{array}$ & $\begin{array}{c}<0.003 \\
1\end{array}$ \\
\hline $\begin{array}{l}\text { Social support } \\
\text { High social support } \\
\text { Moderate social support } \\
\text { Low social support }\end{array}$ & $\begin{array}{c}14(3.3) \\
84(20.1) \\
9(2.1)\end{array}$ & $\begin{array}{c}52(12.4) \\
245(58.6) \\
14(3.4)\end{array}$ & $\begin{array}{c}1 \\
1.27(0.417,3.615) \\
2.39(0.814,6.380)\end{array}$ & & \\
\hline $\begin{array}{l}\text { Planned pregnancy } \\
\text { Yes } \\
\text { No }\end{array}$ & $\begin{array}{l}38(9.1) \\
68(16.3)\end{array}$ & $\begin{array}{c}267(63.9) \\
45(10.8)\end{array}$ & $\begin{array}{c}1 \\
10.62(6.393,17.633)\end{array}$ & $\begin{array}{c}1 \\
4.34(2.345,8.020)\end{array}$ & $\begin{array}{c}1 \\
<0.001\end{array}$ \\
\hline $\begin{array}{l}\text { First ANC } \\
\text { First trimester } \\
\text { Second trimester } \\
\text { Third trimester }\end{array}$ & $\begin{array}{l}13(3.1) \\
73(17.5) \\
20(18.9)\end{array}$ & $\begin{array}{c}129(30.9) \\
174(41.6) \\
9(2.9)\end{array}$ & $\begin{array}{c}1 \\
4.16(2.212,7.836) \\
22.05(8.345,58.268)\end{array}$ & $\begin{array}{c}1 \\
6.23(0.483,9.696) \\
\mathbf{5 . 4 1}(\mathbf{4 . 3 4 5}, \mathbf{1 5 . 2 6 8})\end{array}$ & $\begin{array}{c}1 \\
0.112 \\
0.011\end{array}$ \\
\hline $\begin{array}{l}\text { Abortion } \\
\text { Yes } \\
\text { No }\end{array}$ & $\begin{array}{c}19(4.5) \\
87(20.8)\end{array}$ & $\begin{array}{c}25(6) \\
287(68.7)\end{array}$ & $\begin{array}{c}2.51(0.210,0.759) \\
1\end{array}$ & & \\
\hline $\begin{array}{l}\text { Parity } \\
\text { Nulliparous } \\
\text { Multiparous }\end{array}$ & $\begin{array}{l}34(8.1) \\
72(17.2)\end{array}$ & $\begin{array}{l}160(38.3) \\
152(36.4)\end{array}$ & $\begin{array}{c}0.45(0.282,0.714) \\
1\end{array}$ & & \\
\hline $\begin{array}{l}\text { Gravidity } \\
\text { Primigravida } \\
\text { Multigravida }\end{array}$ & $\begin{array}{c}30(7.2) \\
76(18.2)\end{array}$ & $\begin{array}{l}151(36.1) \\
161(38.5)\end{array}$ & $\begin{array}{c}0.42(0.261,0.678) \\
1\end{array}$ & & \\
\hline
\end{tabular}

had full access to all the data in the study and had final responsibility for the decision to prepare the manuscript and submit for publication.

\section{Conflicts of Interest}

The authors declare that there are no conflicts of interest.

\section{Authors' Contributions}

Berhanu Boru Bifftu was responsible for the manuscript from its conception and analysis and interpretation of data and drafted the manuscript. Berihun Assefa Dachew participated in data analysis and commented on and drafted the manuscript. Bewket Tadesse Tiruneh participated in data analysis and interpretation and review of the manuscript.
Abarham Zeleke Zewoldie participated in data analysis and review of the manuscript.

\section{Funding}

The funding of this paper was covered by the University of Gondar College of Medicine and Health Sciences.

\section{Acknowledgments}

The authors would like to thank the University of Gondar College of Medicine and Health Sciences for the inspiration, motivation, and financial support to conduct this research. They would also like to thank the study subjects for their willingness to participate in the study. Last but not least, heartfelt thanks are due to the supervisors and data collectors. 


\section{References}

[1] U. Nations, "Beijing declaration and platform for action. Paper presented at the Fourth World Conference on Women: Action for Equality, Development and Peace," Beijing, 1995.

[2] WHO, Multi County Study on Women's Health and Domestic Violence Against Women: Initial Results on Prevalence, Health Outcomes and Women's Responses, WHO, Geneva, 2005.

[3] T. L. Taillieu and D. A. Brownridge, "Violence against pregnant women: Prevalence, patterns, risk factors, theories, and directions for future research," Aggression and Violent Behavior, vol. 15, no. 1, pp. 14-35, 2010.

[4] M. Pourasadi and M. Hashemi, "Phenomenon of divorce and custody of children after separation," Biquarterly of Studies of Woman Police, vol. 6, no. 16, pp. 54-81, 2012.

[5] C. Garcia-Moreno, H. A. Jansen, M. Ellsberg, L. Heise, and C. H. Watts, "Prevalence of intimate partner violence: findings from the WHO multi-country study on women's health and domestic violence," The Lancet, vol. 368, no. 9543, pp. 1260-1269, 2006.

[6] S. Shamu, N. Abrahams, M. Temmerman, A. Musekiwa, and C. Zarowsky, "A systematic review of African studies on intimate partner violence against pregnant women: Prevalence and risk factors," PLoS ONE, vol. 6, no. 3, Article ID e17591, 2011.

[7] Survey CSAEaOMEdah, Central Statistical Agency and ORC Macro, Ethiopia, Addis Ababa, Ethiopia, 2011.

[8] Central Statistical Agency (CSA), Ethiopia Demographic and Health Survey: Key Indicators Report Addis Ababa, Ethiopia, and Rockville, Maryland, USA, CSA and ICF, 2016.

[9] S. G. Abeya, M. F. Afework, and A. W. Yalew, "Intimate partner violence against women in western Ethiopia: prevalence, patterns, and associated factors," BMC Public Health, vol. 11, article 913, 2011.

[10] Y. Gossaye, N. Deyessa, Y. Berhane et al., "Butajira Rural Health Program: Women's Health and Life Events Study in Rural Ethiopia," Ethiopian Journal of Health Development, vol. 17, no. 5, 2004.

[11] T. Yimer, T. Gobena, G. Egata, and H. Mellie, "Magnitude of Domestic Violence and Associated Factors among Pregnant Women in Hulet Ejju Enessie District, Northwest Ethiopia," Advances in Public Health, vol. 2014, pp. 1-8, 2014.

[12] B. Abebe Abate, B. Admassu Wossen, and T. Tilahun Degfie, "Determinants of intimate partner violence during pregnancy among married women in Abay Chomen district, Western Ethiopia: A community based cross sectional study," BMC Women's Health, vol. 16, no. 1, article no. 16, 2016.

[13] Z. Y. Kassa and A. W. Menale, "Physical violence and associated factors during pregnancy in Yirgalem town, South Ethiopia," Current Pediatric Research, vol. 20, no. 1-2, pp. 37-42, 2016.

[14] Secretary TWHOotP, Presidential Memorandum - Establishing a Working Group on the Intersection of HIV/AIDS, Violence Against Women and Girls, and Gender-Related Health Disparities, Establishing- Working-Group-Intersection-HIV/AIDS, 2015, https:/www.whitehouse.Gov/the-press-office/2012/03/30/ presidential-memorandum.

[15] D. H. McCree, L. J. Koenig, K. C. Basile, D. Fowler, and Y. Green, "Addressing the intersection of HIV and intimate partner violence among women with or at risk for HIV in the United States," Journal of Women's Health, vol. 24, no. 5, pp. 331$335,2015$.

[16] G. D. Zimet, S. S. Powell, G. K. Farley, S. Werkman, and K. A. Berkoff, "Psychometric characteristics of the multidimensional scale of perceived social support," Journal of Personality Assessment, vol. 55, no. 3-4, pp. 610-617, 1990.

[17] D. K. M. Kaye, G. Bantebya, A. Johansson, and A. M. Ekstrom, "Domestic violence during pregnancy and risk of low birth weight and maternal complications:a prospective cohort study at Mulago Hospital, Uganda," Tropical Medicine \&a International Health, vol. 11, pp. 1576-1584, 2006.

[18] B. Olagbuji, M. Ezeanochie, A. Ande, and E. Ekaete, "Trends and determinants of pregnancy-related domestic violence in a referral center in southern Nigeria," International Journal of Gynecology and Obstetrics, vol. 108, no. 2, pp. 101-103, 2010.

[19] S. Shamu, N. Abrahams, C. Zarowsky, T. Shefer, and M. Temmerman, "Intimate partner violence during pregnancy in Zimbabwe: A cross-sectional study of prevalence, predictors and associations with HIV," Tropical Medicine \& International Health, vol. 18, no. 6, pp. 696-711, 2013.

[20] J. Ntaganira, A. S. Muula, F. Masaisa, F. Dusabeyezu, S. Siziya, and E. Rudatsikira, "Intimate partner violence among pregnant women in Rwanda," BMC Women's Health, vol. 8, article 17, 2008.

[21] M. Hoque MEH and S. Kader, "Prevalence and experience of domestic violence among rural pregnant women in KwaZuluNatal, South Africa," Southern African Journal of Epidemiology \& Infection, vol. 24, no. 4, pp. 34-37, 2009.

[22] A. Ashimi and T. Amole, "Prevalence and predictors for domestic violence among pregnant women in a rural community Northwest, Nigeria," Nigerian Medical Journal, vol. 56, no. 2, p. 118, 2015.

[23] L. A. Makayoto, J. Omolo, A. M. Kamweya, V. S. Harder, and J. Mutai, "Prevalence and associated factors of intimate partner violence among pregnant women attending Kisumu District Hospital, Kenya," Maternal and Child Health Journal, vol. 17, no. 3, pp. 441-447, 2013.

[24] E. Valladares, R. Peña, L. Å. Persson, and U. Högberg, "Violence against pregnant women: Prevalence and characteristics. A population-based study in Nicaragua," BJOG: An International Journal of Obstetrics \& Gynaecology, vol. 112, no. 9, pp. 12431248, 2005.

[25] A. N. I. Gyuse and A. P. Ushie, "Pattern of domestic violence among pregnant women in Jos, Nigeria," South African Family Practice, vol. 51, no. 4, pp. 343-345, 2009.

[26] Z. Iliyasu, I. S. Abubakar, H. S. Galadanci, Z. Hayatu, and M. H. Aliyu, "Prevalence and Risk Factors for Domestic Violence Among Pregnant Women in Northern Nigeria," Journal of Interpersonal Violence, vol. 28, no. 4, pp. 868-883, 2013.

[27] M. Salazar and M. San Sebastian, "Violence against women and unintended pregnancies in Nicaragua: A population-based multilevel study," BMC Women's Health, vol. 14, no. 1, article no. 26, 2014.

[28] C. C. Pallitto, C. García-Moreno, H. A. F. M. Jansen, L. Heise, M. Ellsberg, and C. Watts, "Intimate partner violence, abortion, and unintended pregnancy: Results from the WHO Multicountry Study on Women's Health and Domestic Violence," International Journal of Gynecology and Obstetrics, vol. 120, no. 1, pp. 3-9, 2013.

[29] N. Thananowan and S. M. Heidrich, "Intimate partner violence among pregnant thai women," Violence Against Women, vol. 14, no. 5, pp. 509-527, 2008.

[30] K. Birmeta, Y. Dibaba, and D. Woldeyohannes, "Determinants of maternal health care utilization in Holeta town, central Ethiopia," BMC Health Services Research, vol. 13, article 256, 2013. 


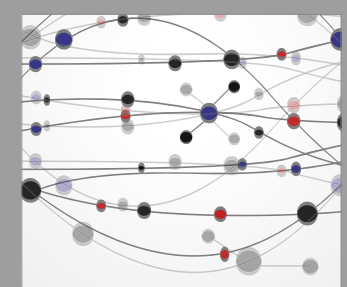

The Scientific World Journal
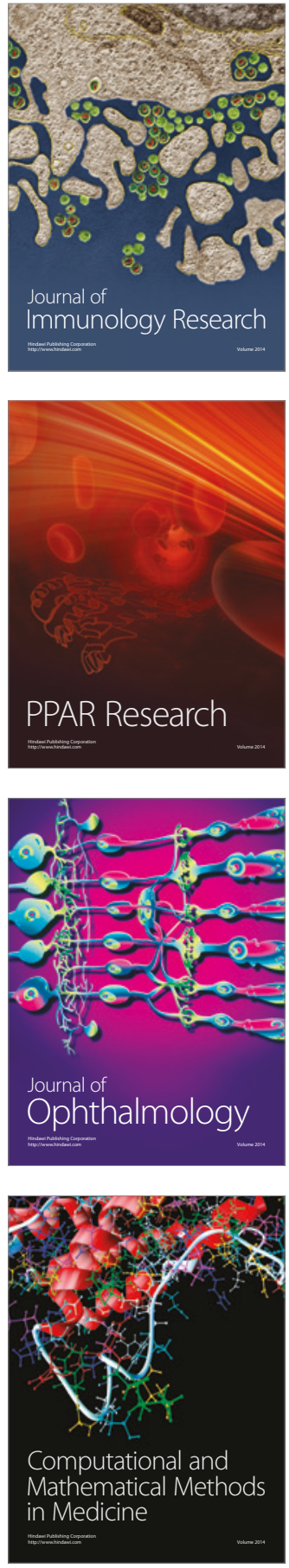

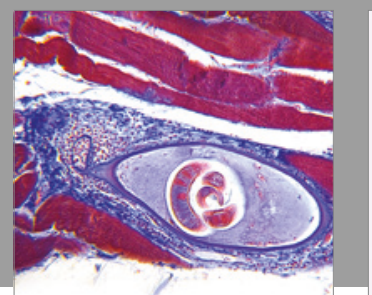

Gastroenterology Research and Practice
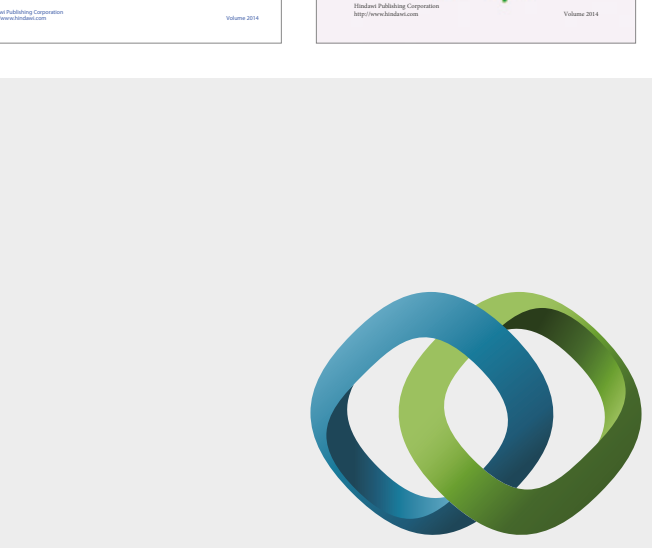

\section{Hindawi}

Submit your manuscripts at

https://www.hindawi.com
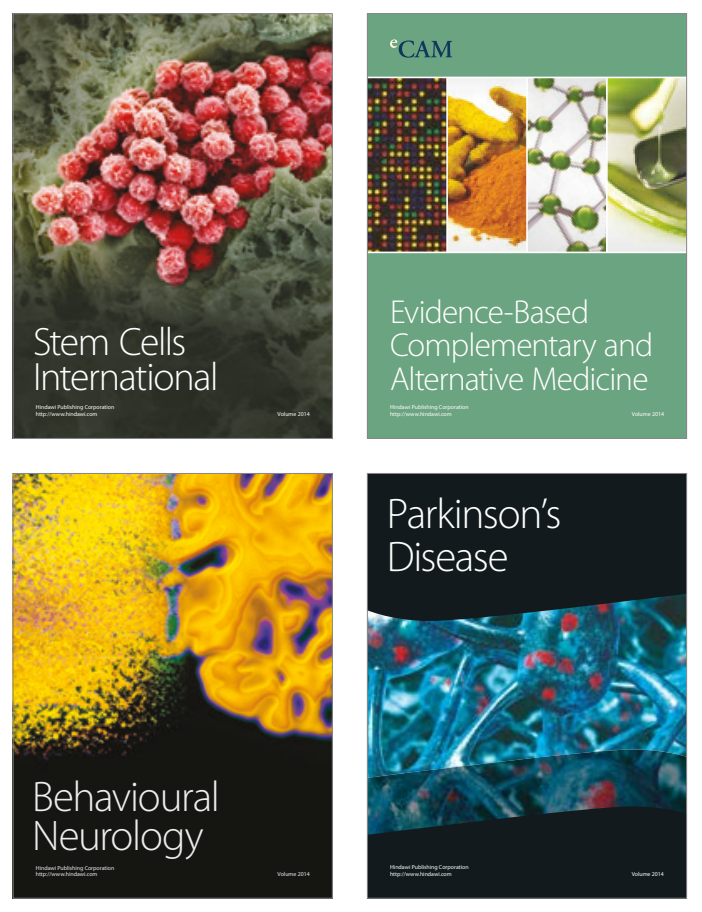
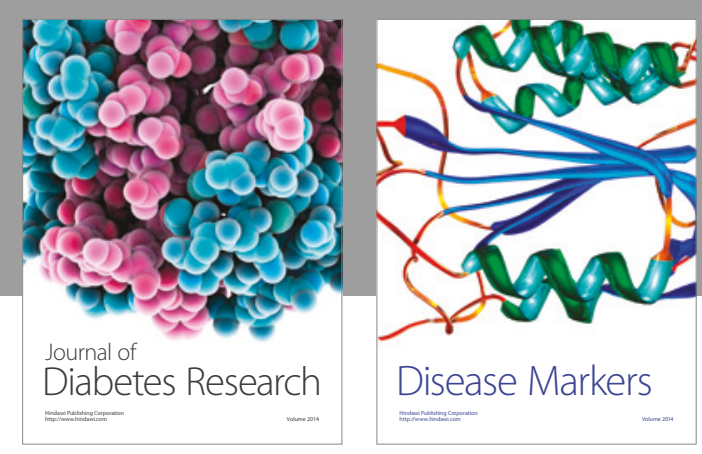

Disease Markers
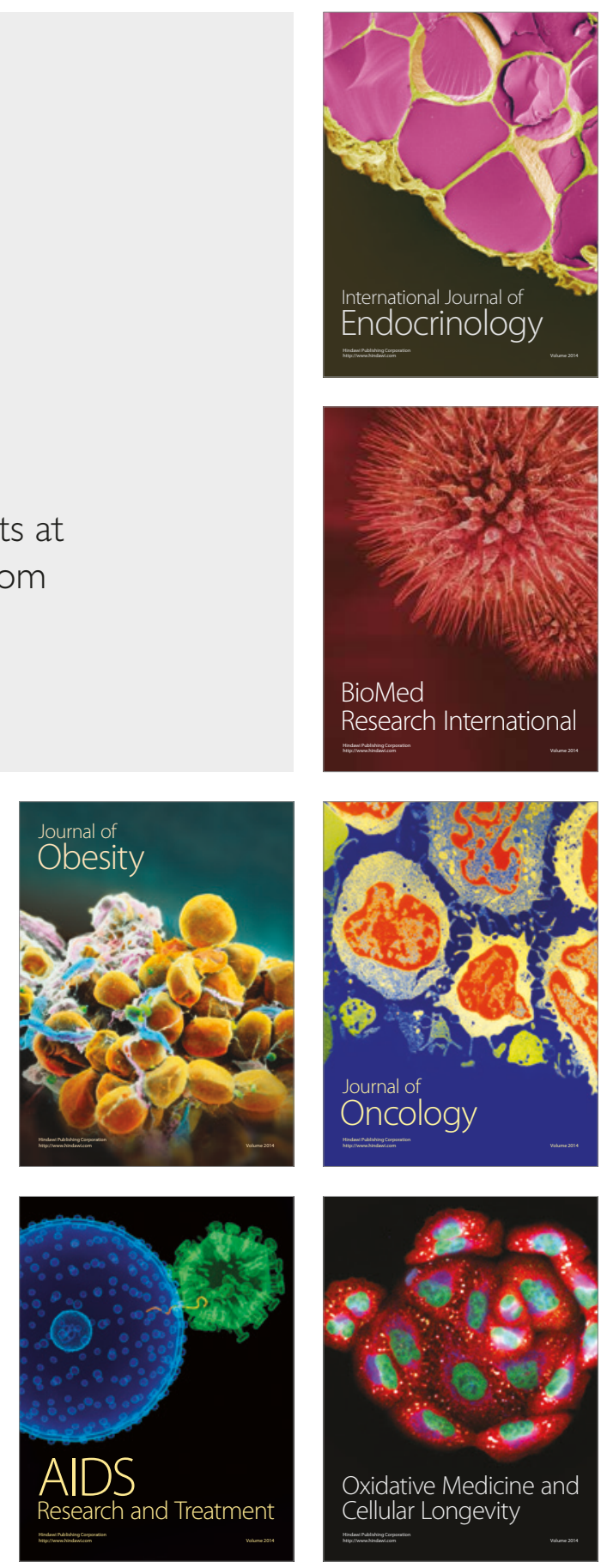